\title{
Burkhard Schäfer
}

\section{LEŚNIEWSKI-QUANTIFIERS AND MODAL ARGUMENTS IN LEGAL DISCOURSE}

\begin{abstract}
Following an idea first proposed by Jerzy Wróblewski, this paper examines the usefulness of formal logic for comparative legal analysis. Subject of the comparison are the doctrines of mistake and attempt in German and English criminal law. These doctrines are distinguished by the interaction of deontic, epistemic and alethic modalities. I propose a purely extensional logic which is based on Leśniewski's substitutional interpretation of quantification to analyse differences in the logical structure of the various criminal law doctrines.
\end{abstract}

\section{CONTENTS}

1. Introduction, p. 134

2. Law Lords out of their noble minds?, p. 136

3. Outline of the formalism, p. 149

4. Semantics, p. 150

5. Evaluation from a comparative perspective, p. 152

Received October 2, 1998 


\section{Introduction}

One of the first things a student of comparative law has to learn is the divide between continental (civilian) and common law jurisdictions. ${ }^{1}$ Secondly, so she is told, this divide corresponds to a difference in importance of logic and logical reasoning. Continental law is said to be quintessentially logical, common law a-logical. ${ }^{2}$ This now is a quite remarkable statement. The very same lawyers who quickly label an entire legal system (and its practitioners) as a-logical, will normally deny under oath any knowledge of logic altogether. Judex non calculat is an old legal proverb, and ignorance of (formal) logic, in common law and continental jurisdictions, is often taken as proof positive of common sense, and as a source of professional pride. The comparative lawyer acts a bit like the person who denies any knowledge of art, but insists that she knows what she likes. "I don't know what logic might be, but I recognise a logical legal system if you show me one". For post-Montague logicians, the whole debate probably brings back memories from times past. Unsurprisingly, the myth of the logical nature of continental law dates back to the rough days of logical positivism and a perception of logic which is seen, if not as the stairways to heaven, so the stairways to the heaven of concepts. A distorted picture of the natural sciences as axiomatic disciplines, and logic as normative rather then descriptive endeavour informed the great codification movement on the continent. True, the idea of a legal science was more predominant on the continent, and it is equally obvious that this attempt resulted in considerable differences between continental and common law systems. We must doubt however if logic is the right means to express this difference. Legal English is no less a formal language than English proper. To use formal methods to analyse the differences between legal systems is however tempting for a completely different reason. Comparative linguistics has undoubtedly profited from the introduction of formal methods by Chomsky. Comparative law, notoriously weak in its theoretical foundations, could equally profit from the introduction of rigorous conceptual tools. Maybe the first to use logical analysis for a purely descriptive, non-judgemental comparison between common law and continental law

\footnotetext{
${ }^{1}$ For readers not acquainted with this distinction: the civilian legal family includes France and Germany, while England and the US are examples for common law jurisdictions. Cf. Zweigert Kötz 1992, p. 63 ff.

${ }^{2}$ Cf. Legrand 1995 with further references.
} 
was the doyen of Polish legal philosophy, Jerzy Wróblewski. Back in 1974, he tried to give a comparative logical analysis of the main forms of argumentation in common law systems and continental systems of law. ${ }^{3}$ And, contradicting the conceived wisdom of this time, he refrained from labelling the common law as illogical. Rather, he claimed that common law, with its emphasis on case based reasoning, displayed a different, but by no means inferior logical structure. Is common law then not so much "logically challenged", but rather "differently logical"? And is this really more than to label the class bully "differently gifted", i.e. gifted for all sorts of disruptive behaviour? Unfortunately, Wróblewski's analysis remains inconclusive. He distinguishes "analogical" from deductive reasoning, but the analysis that he proposes for the "analogical" common law is, at best, a semi-formal one. Comparison of the formal properties of the two systems remains impossible - at least if we want to carry out such a comparison again in a formal setting. Secondly, we have by now systems for the computer modelling of legal reasoning, which try to incorporate the difference between case based and rule based reasoning in a strictly formal way. And the experience with these systems shows that they work for both legal families best, when we combine the two approaches. However, in what follows I want to revive Wróblewski's idea of logic as a means for the comparative analysis of legal argumentation. But instead of trying to define globally differences in the nature of the inference relation, I will analyse the logical structure of important legal premises. That is, I will ask the question whether we can find, within a given logical framework, systematic differences in the logical form of legal rules, which on the syntactical surface structure look identical. Or conversely, examples where we can find a similar logical deep structure despite apparent differences in the legal vocabulary. The analysis will focus on multi-modal legal arguments, legal arguments where modalities of different types interact. Typically, we find this sort of argumentation in the criminal law doctrines of mistake and attempt. I attempt to commit a crime if I believe that my behaviour amounts to doing something that is prohibited. Or if I believe to do something which in fact is prohibited. That what I attempt to do might be impossible, and German and English law develop special responses to this unusual case. Furthermore, I might or might not know that my attempt to break a certain prohibition is impossible - I might for instance try to convince you that my target is out of range. Does there have to be at least some object at which my attempt is directed - even if

\footnotetext{
${ }^{3}$ Cf. Wróblewski 1974, 1983, p. 164 ff.
} 
I refer to the object under a wrong description? Again a problem discussed in English and German criminal law doctrine. The interaction of different modalities in all these questions gives rise to systematic natural language ambiguities. These allow different legal systems to disambiguate them in different ways. One of the questions to be asked will be if legal systems do this in a systematic way, if they prefer consistently one reading to the other.

In the first part, I will give a more detailed informal analysis of modal arguments in the law of attempt. In the second part, I will introduce a formal system, which can represent the different ways to disambiguate the natural language notion of "attempt" and "belief". The logic used is based on a proposal by Ulrich Blau (see Blau 1993), and I used a similar approach to analyse the notion of misrepresentation in German and English contract law (see Schäfer 1993). Recently, it became however obvious to me that the formalism is in a number of ways similar to that proposed in Leśniewski's "ontology", especially in its further developed version by Ajdukiewicz. Based on a free logic, it allows (substitutional) quantification into modal contexts. Following again Leśniewski, it will be equally possible to quantify (again substitutionally) over predicate(symbols) and sentences. Deviating from his proposal, the logic under investigation here will contain mixed variables. Referentially interpreted variables are restricted to extensional argument positions, substitutional variables allow quantification into arbitrary argument positions. ${ }^{4}$ Nevertheless, the version of substitutional quantification that I will propose could equally be understood as an attempt to offer natural language motivation for his approach and to clarify these notoriously contested notions in his philosophy. ${ }^{5}$

\section{Law Lords out of their noble minds?}

This is the story of Roger Smith, a hapless fence and petty thief, who was to become a legal (and logical) enigma. 1973 seemed to become a particularly bad year for the business activities of this gentleman, when the "agents of uniformed social control" finally laid their heavy hands on his shoulders. The police had set up a textbook trap for him. Two of his business associates were caught driving a van full of stolen corned beef, and, interrogated, admitted that they were about to drive the loot to a place where Roger Smith would

\footnotetext{
${ }^{4}$ On referential and substitutional quantification cf. Linsky, 1972 p. 224-238.

${ }^{5}$ For this debate cf. Küng, Canty 1970, Kielkopf 1977, Küng 1977, Simons 1982.
} 
take charge of it and sell it on the black market. The police ordered them to drive on, themselves hidden in the back of the van. In the moment when Smith laid his hands on the corned beef, he was arrested and charged with attempt to handle stolen goods. We may safely assume that in this moment, Smith was sure he would spend the coming year behind prison bars. Alas, he would have been mistaken. Reason for his remarkable acquittal in the court of appeal was the combination of another mistake he had made, the appeal judges in their more inventive mood, and a very clever lawyer. This is a reconstruction of his argument. ${ }^{6}$

To be guilty of a criminal attempt, an agent must act "with intent to commit an offence" (so far, the legal provisions of most, if not all, modern legal systems agree). Intent to commit an offence is frequently understood as the belief that one commits an offence and the desire of the outcome of this act. Both are questioned here. Smith tried to handle goods - so far, defence and prosecution agree. Where they disagree is whether he also tried to handle stolen goods. In the moment the police seized the corned beef, they repossessed it on behalf of the owner. That means it instantaneously became - in law - the property of its rightful owner again. Therefore, so the defence, Smith attempted to handle totally legitimate goods before the police so cruelly interrupted him. And this is not a crime. Because Smith was mistaken about the legal status of the goods at hand, he could not possibly have committed the crime. It must not be impossible to commit an offence (do something prohibited) in order to attempt to commit the offence. Even if the police had not interrupted Smith and let him sell the corned beef, he would still not have committed the offence. And this despite the fact that he then would have done everything he thought to be necessary to reach the desired result. Consequently, in the moment the police seized the corned beef it became impossible for Smith to handle it as stolen corned beef. This argumentation has consequences for the intent required incurring criminal liability. Since "intent to commit offence $x$ " is in law normally analysed as "believing to do $x$ " and "wanting to do $x$ ", an appropriate interpretation of the belief predicate could ensure the right result. In order to commit an attempted crime, I must believe that my actions, if carried out, amount to doing something prohibited. If I already believe that my actions can impossibly have the prohibited result, I do not attempt to do something prohibited. So far, probably defence and prosecution would agree. But the defence required something stronger: I must not believe doing something

${ }^{6}$ Smith 1975 AC 476. Cf. also Williams 1978, p. 392 ff. 
which is in fact impossible, whether I'm aware of this impossibility or not. An external description by an informed observer of the events in 1973 would have looked like this: Smith waned to take the corned beef in front of him. This corned beef was not stolen. He was interrupted in handling it, therefore he (only) attempted to handle legitimately owned corned beef . The appeal judges were convinced by this argumentation. Making explicit reference to the ordinary language meaning of attempt, and the "logic" of the notion of belief, they conclude that Smith did indeed not attempt to handle stolen goods. Nor did he, and this is maybe more controversial, believe to handle stolen goods. And because they were so fascinated by their own analysis, they gave a list of cases, which, according to them, described the notion of criminal attempt in a prototypical manner.

No criminal attempt was committed, so this list, if

a) I want to steal an umbrella, but I happen to take by mistake my own.

b) I put my hand in another persons empty pocket, to steal money which I mistakenly believe would be there.

c) I fire at a corpse, in the belief it were a living human being.

d) Colonel Moran fires at a wax effigy of Sherlock Holmes, believing to kill the famous detective.

e) I marry a woman thinking that my former wife is still alive. In fact, she had died before (no attempted bigamy).

f) I give you something to eat, in the mistaken belief it is poisoned. You drop the plate. I only attempted to feed you, not to poison you.

On the other hand, attempted crimes were committed when

1) I attempt to break in a house and find out that my jemmy is not good enough,

2) I shoot at someone just out of range,

3) I wound someone with intent to kill, who survives.

These distinctions might appear arbitrary and unworkable. They surely became subject of derisory criticism, by academic lawyers and legal philosophers alike. And in the same way in which the Law Lords justified their decision with reference to the "logic of natural language" (i.e. not at all), their critics accused them of violating the very same laws. Glanville Williams brings it to the point:

It seems to me that Lord Hailsham and the rest of their noble Lordships are hopelessly confused in their noble minds between what is in the villain's contemplation and what is actually the case. Sometimes they seem to look at one, sometimes at the other. (Williams 1978, p. 396) 
Hart comes to a similar conclusion, when he translates these findings into the familiar philosophical jargon. The Lords are mistaken to assume that logic requires that the inference from $P a$ to $\exists x P x$ were valid for arbitrary predicates $P$. As we have seen, the legal debate focuses around modal notions and their interaction. Modal expressions, as is of course well known, are non-extensional and require propositions and not extensions as their arguments. But before we prematurely take sides and criticise the Law Lords from the vantagepoint of linguistic philosophy, let's have a look at the problem from a comparative perspective. Present day German criminal law clearly takes side with Williams. All of the cases stated above would result in a conviction for attempt, and Smith would not stand a chance. English law, after considerable resistance by the judiciary, has by now followed this lead. But in 1913, the eminent German lawyer Binding criticised the German Court of appeal for

And so (the law of mistake) fights with a poisoned weapon against

reality, logic and justice - and slays them all. (Binding 1918, p. 176)

Language reminiscent of Williams' attack in Britain. What did the German appeal judges do to deserve such a contemptuous remark? Well, they had in cases not unlike that of Smith convicted the accused. It is apparently difficult for humble judges to please their academic colleagues - especially if these have enjoyed basic logical training. Since now both sides claim the eternal truth of logic to favour their cause, it seems appropriate to transfer the case to an "expert witness". Given the similarities in the debates in Britain and Germany, I think we should start with the (refutable) assumption that no side holds a totally irrational position. All parties involved in the debate agree on one point. If there is a legal norm that prohibits a certain action $a$, short $P a$, then in order to be liable in law, you must also believe that you are breaking this norm. Indeed, the relevant premises, which have to be established to ensure a conviction, seem to be perfect translations of each other. To facilitate the discussion, let's for the time being introduce a fictitious case where, unlike in Roger Smith, the mistake is not primarily about a certain predicate (being stolen), but about the existence of a person. This brings the case closer to Kripke's famous "Pierre" case, but the main reason is to get better natural language examples. Our original Roger Smith will in the end be treated as but one of the combinatorically possible mistake scenarios $S$, a jealous husband, wants to kill a person he knows only as " $D$ ". He found a letter from his wife to an "agony aunt", speaking about her unsatisfactory emotional relationship with said $D$. Convinced that $D$ is his rival, he plants a bomb to kill him. Let's now assume that $S$ is convicted 
for attempted homicide. Then the following holds under English in the time when Roger Smith was good law, and under contemporary German law: English (E): $S$ attempted intentionally to kill $D$.

German (G): $S$ versuchte vorsätzlich, $D$ zu töten.

Again from a comparative perspective, we might be tempted to assume that both systems are sufficiently similar. Direct translation fails often even if the systems are virtually identical from a legal perspective. If it is possible, as in the case at hand, we have at least a strong presumption for deeper similarity. Logical analysis now shows that both sentences have a different logical deep structure. From E, we can infer that D exists. Otherwise, the attempt would have been impossible. Under German law, no such inference is possible. Both systems require the belief to violate a norm. But what exactly does that mean? From a logical point of view, both sides have something to say: the Lords obviously intend a de re reading of belief and attempt. To use Quine's proposal for a de re paraphrase: in order to be culpable of attempted murder, you must believe of somebody that your actions are likely to kill him (see Quine 1956). Admittedly, the paraphrase is much less natural for the attempt predicate proper. But there is an old usage of attempt, as in "the army made an attempt on the fortress", which is obviously de re and referential. German law, and the British critics of the Law Lords, prefer a de dicto reading: it is enough that I believe "I kill John", no matter if John really exists. And it is sufficient that I believe that the goods in front of me are stolen, whatever their legal status might be in reality. This mirrors Williams' remark quoted above: For this position, the only relevant facts can be found in the villain's mind. Informally, we can see already that both sides are equally right and wrong. Outside the legal field, there are plenty of natural language examples that show that both readings are possible. Columbus clearly believed that America was an Asian island, even if we do not find (the word, concept, propositional type?) "America" in his head. Substitution of "America" for co-referential expressions is possible: he equally believed of the second largest continent that it were an Asian Island. In this sense, the Lords are immune from William's criticism: it is acceptable and sometimes necessary to keep both in mind, internal contemplation and external facts. On the other hand, Pizarro believed to find his luck in El Dorado. And here, substitution of "El Dorado" for a co-referential place is impossible. He did not believe for instance to find his luck in Walhalla.

I propose a logic with mixed quantifiers, which follows, more in spirit than in words, ideas developed by Leśniewski. Leśniewski's determined nominalism resulted in a rejection of the referential interpretation of quanti- 
fiers. Names for non-existing objects, or "meaning" in the form of linguistic entities however can be freely added to the universe of discourse. Already Ajdukiewicz saw the potential of this approach for the analysis of intensional contexts, and refined Leśniewski's ontology to take the distinction between real and intentional objects into account (cf. Dolling, 1995). I will return to the similarities between the solution proposed here and the Ajdukiewicz-Leśniewski formalism after I have introduced an outline of a logic, which I think can make the differences between German and English, law transparent. Alethic, deontic and epistemic expressions are interpreted as predicates, not as operators. Modal predicates take a special kind of structured objects, sentences, as their arguments. The resulting logic has much in common with quotational approaches to epistemic logic, even if no quotation function is introduced explicitly. ${ }^{7}$ Each predicate carries a type $\tau=$ "." or "o", indicating whether its argument position is interpreted referentially $(\bullet)$ or substitutionally (o). Correspondingly, we distinguish de re and de dicto variables $x^{\bullet}$ and $x^{\circ}$. De dicto variables correspond closer to Leśniewski's uniform variables. Consequently, a sentence of the form $\exists x^{\circ} P^{\circ} x^{\circ}$ is true if we can find a name which when substituted for the bound variable yields a true sentence. ${ }^{8}$ The predicate $P$ could stand for instance for the property of being mystical. If the name "Santa Claus" is in our universe of discourse, the sentence is true. Since identity is of the de re type, it is in particular not possible to express the idea that Santa Claus is also the person which comes once a year through the chimney. Speculations about attributes of the object commonly associated with Santa are neither necessary nor possible in this framework. Since it depends on the type of the predicate whether a certain parameter is interpreted referentially or substitutionally, irreferential expressions are allowed. Like Leśniewski's ontology, the result is a free logic. Following an idea by Dunn and Belnap (1969), I use the signs of the object language autonomously and I do not restrict the substitution to proper names, but include other entities, most notably sentences, as substitutes. Again, this is in line with Leśniewski's treatment of quantification. ${ }^{9}$ Sentences are structured objects in our universe of discourse, and to some extend, they violate the principle of compositionality. ${ }^{10}$ If they occur as sub-

\footnotetext{
${ }^{7}$ On quotational approaches cf. Wray, 1987 p. 77-110.

${ }^{8}$ Cf. Kotarbiński 1966, p. 190.

${ }^{9}$ See Leśniewski 1929, p. 12. Cf. also Srzednicki and Rickey 1984.

10 Therefore, typical objections against the related quotational approach to belief as expressed by e.g. Cresswell 1980 do not apply.
} 
stitutes in de dicto positions, then the truth-value of the complex sentence is not determined by the values of the constituents of this sentence-object. But they are structured, and therefore, quantification into these sentence objects is possible. ${ }^{11}$

The reason to formalise modal expressions as predicates, and to avoid the normal operator based approach, is one of ontological commitment. Not because of any philosophical prejudices by the author, but because of the methodological requirements of a comparative approach. Legal language is not philosophically innocent. Legal doctrine, through various forms of interaction between the disciplines, embodies the philosophical wreckage of centuries. A comparative analysis must be true to these influences. But philosophical ideas influenced different legal systems in different ways, and sometimes even different parts of the same legal system differently. The English law against fraud for instance displays similar examples of modal arguments. It is prohibited to make you believe that I am Bill Gates, if I abuse your mistake for borrowing money from you. Apparently, this is not at all the same (in law) as making you believe that I am filthy rich. Strange creatures inhibit the world of English fraud law, for instance the non-existent banker who backs a fraudulent investment scheme. And legal debate, Quine notwithstanding, will have to address the question whether this non-existent banker has certain necessary and certain contingent properties. Nothing comparable happens in the discussion about impossible attempts. Possible worlds seem absolutely appropriate to analyse this part of legislation. On the other hand, it is also a highly contested part of English criminal law, and it is not at all clear whether it is consistent with the more general deliberations about intent and belief which concern us here. To be able to preserve this distinction, the approach proposed here sacrifices neatness of the formal meta-theory for ontological puritanism.

The working of this formalism is best understood if we look at some examples. In our example above, we had the situation that a person, let his name be John Doe, wants to kill another person, John Dee, whom he suspects to be a rival. He has carried out everything necessary for the preparation of his evil deed, when he is apprehended by the police. To ensure conviction, both in Germany and Britain, it must be ascertained that Doe believed that his actions, if uninterrupted, would result in the killing of Dee. "Murder", in its normal usage, is both referential and extensional. You kill only existing people, and if you were to kill the only German in the Law Fac-

${ }^{11}$ A similar understanding of complex substitutes was proposed in Haack 1974. 
ulty of Edinburgh University, you would also kill me. This fact is therefore formalised with de re predicates, as

$$
M^{\bullet \bullet}(a, b) .
$$

Here, the de re types guarantee that both argument positions are interpreted referentially.

Doe now forms a belief about this sentence. As indicated above, sentences are treated as complex objects that can occur at de dicto argument positions. Unsurprisingly, the belief predicate has in its second position a de dicto-type.

$$
B^{\bullet \circ}\left(a, M^{\bullet \bullet}(a, b)\right)
$$

with $B$ - believes; $M$ - murders; $a$ - John Doe; $b$ - John Dee.

Admittedly, this is for a number of reasons not a very convincing formulation, if only for the occurrence of " $a$ " within the that-complement. Doe is not very likely to refer to himself using his proper name. But for the purpose of this exercise, it will do. It is not very likely that we will learn more about the relevant legal doctrines by getting a better understanding of the logic of personal pronouns. Offenders with multiple personality disorder could pose a problem, but they will generally not incur criminal liability at all.

Formulation (2) leaves it open whether John Dee exists. In our fictitious example above, the only knowledge Doe has about his assumed rival is his name, which he found in a letter by his wife. (2) now holds true for two possible endings of our sad little story. According to the first, there is indeed a John Dee who has an amorous affair with Doe's wife. Dee believed that his actions were likely to kill him, and we get liability for attempted homicide in both German and English law. That a name occurs at a de dicto position does not necessarily mean that it is irreferential. But (2) would also be true if the following were the case. Doe's wife, deeply unhappy with her marriage with her jealous husband, asks an agony aunt for advice. In fear that the letter might get published, she changes the names of the persons involved, and in particular, she refers to her husband under the alias "John Dee" - and to spare embarrassment to third parties, she makes sure that nobody else has this name. (2) is still true, the inference of "There is someone whom Doe wants to kill" is blocked. Furthermore, de dicto positions are referentially opaque, and therefore, no substitution of "John Dee" by "invented Person" or indeed "John Doe" would be possible in this situation. If a legal system links punitive sanctions to one's belief that one's actions result in the violation of a norm, and if belief is understood as in (2), then 
the question whether the person or thing threatened by one's illegal actions actually exists is legally irrelevant. This is now indeed the situation under German law, where Dee would face prosecution for attempted murder in both variations of the story. Secondly, we note that it is possible to quantify into the de dicto position in (2) - as long as we use de dicto variables. This is necessary since legal norms are usually formulated in general terms and cover typically more then one situation. In the present situation, this means that we can express ideas as:

$$
\exists x^{\circ} B^{\bullet \circ}\left(a, M^{\bullet \bullet}\left(a, x^{\circ}\right)\right)
$$

A more complete natural language version of (2) would be: John Doe believes to kill John Dee-de dicto, i.e. something under the description "John Dee". (2) then expresses the idea that Doe believes under some description that he is going to murder someone. In this form, it is suitable for the antecedents of a general legal norm, for instance

$$
\forall y^{\bullet}\left(\exists x^{\circ} B^{\bullet \bullet}\left(y^{\bullet \bullet \bullet}, M^{\bullet \bullet}\left(y^{\bullet}, x^{\circ}\right)\right) \rightarrow A y^{\bullet}\right)
$$

with $A$ - Guilty of attempted murder

Since modern criminal law convicts only existing people, the subject position is de re. ${ }^{12}$ Note however that the second occurrence of " $y$ " is still in a de dicto position. It depends entirely on the predicates, and not on any stipulated identity criteria for intensional objects, if substitution is admissible. Obviously, (3) holds also true in the case of Roger Smith. According to the analysis developed so far, he believed to handle stolen corned beef-de-dicto, the fact that is was not-stolen-de-re notwithstanding. And there is no doubt that he would have been convicted for attempting to handle stolen goods under German law. ${ }^{13}$ Consequently, (4) cannot be a rule of the English legal system.

The Law Lords apparently had a de re reading in mind. Two things must be guaranteed here. The first is relatively simple: we must make sure that we can infer from the belief to kill " $a$ " the existence of " $a$ ". Secondly, and this will be the more difficult part, we must assure that the perpetrator

\footnotetext{
12 This is not trivial! Medieval law would sometimes convict "demons" who had taken over animals. The animal was destroyed, but the demon convicted.

${ }^{13}$ Cf. e.g. K. Geppert, "Zum 'error in persona vel objecto" und zur 'aberratio ictus', insbesondere vor dem Hintergrund der neuen 'Rose-Rosahl-Entscheidung'" in: Jura 1992, p. 163. C. Prittwitz, "Zur Diskrepanz zwischen Tatgeschehen und Tätervorstellung" in: Goltdammer's Archiv für Strafrecht 1983, p. 110 (zit.: GA, Jahrgang, Seite).
} 
refers to his object under a legally relevant description. One first attempt of a formal version could look like this:

$$
\exists x^{\circ}\left(x^{\circ}=b \& B^{\bullet \circ}\left(a, M^{\bullet \bullet}\left(a, x^{\circ}\right)\right)\right)
$$

$b$ - John Dee.

A natural language translation of (5) would be: John Doe believes of Dee that his bomb is going to kill him. The existence of John Dee is here guaranteed by the de re identity outside any de dicto type. This shows one of the main differences between the proposal here and similar attempts to interpret belief substitutionally. It is possible to quantify with de dicto quantifiers into de re position, and the variable is then interpreted referentially. Again this expresses the idea that it depends on the predicate, not on any abstract considerations about the identity of intensional objects, how variables are to be interpreted. (5) might still be too weak. It requires only that Doe believes of Dee under some description that he kills him. In cases of mistakes however, the description might be legally relevant. I shoot at the source of noise in a bush (believing maybe that it is deer). In fact, that source of noise is the local game warden. According to (5), I believed (and therefore attempted) to shoot the local game warden. This is indeed under both legal systems a relevant mistake that would - given that the mistake was not unreasonable - exclude liability. A very strict requirement would demand that I could identify the object de re as the one described de dicto. Put it differently, I have to know the warden as the source of noise, or formally:

$$
\exists x^{\circ}\left(x^{\circ}=b \& B^{\bullet \circ}\left(a, M^{\bullet \bullet}\left(a, x^{\circ}\right)\right) \& K^{\bullet \bullet \bullet}\left(a, x^{\circ}, b\right)\right)
$$

This seems to be indeed a more accurate description of what the Lords had in mind. It guarantees the existence of the object of the criminal act, and it guarantees that my intent to violate the norm was formed in a relevant way. To some extend, it begs the question, of course. "Knowing-as" is at least as problematic as "believe".

It is now time for a short summary. We started with natural language expressions, which superficially seemed to be perfect translations of each other. It turned out that hidden under this superficial similarity, there are considerable differences in logical structure. "Smith believed to handle stolen goods" could mean either believed-de re, (the English version), or believed de dicto, preferred reading of the German criminal law.

Smith believed to handle stolen goods

$$
B^{\bullet \bullet}\left(s, H^{\bullet \bullet}(s, b)\right)
$$

(German law, and the case in the historical example.) 


$$
\exists x^{\circ}\left(x^{\circ}=b \& B^{\bullet \circ}\left(a, M^{\bullet \bullet}\left(a, x^{\circ}\right)\right) \& K^{\bullet \bullet \bullet}\left(a, x^{\circ}, b\right)\right)
$$

(English law, and not the case in the historical example.)

A meaning postulate which captures the usage of the belief predicate in both examples could be the following: $B^{\bullet \bullet}\left(s, H^{\bullet \bullet}(s, b)\right)$ means that $s$ would (under sufficiently ideal conditions, after enough time of consideration) accept a translation of the sentence " $H \boldsymbol{\bullet}^{\bullet}(s, b)$ " into his mental language as sufficiently certain. This would mirror the legal requirements: the court procedures guarantee (ideally) sufficient time and information, and the legal requirement demands only "without any reasonable doubt" and leaves room to ignore particularly eccentric idiolects.

I will try at the end of this paper to give some tentative informal evaluation of these findings.

Firstly, however, we must look at some complications of the picture developed so far. One of the features of de dicto belief is that it takes referential opaqueness seriously. It is generally not possible to substitute expressions in de dicto positions for co-referential, or indeed co-intensional descriptions. Furthermore, it is not a logical requirement of the system that believes are consistent or closed under deduction. It is, at least in principle, possible that $B^{\bullet \circ}(s, a=b)$ and $B^{\bullet \circ}(s, a \neq b)$ are both true for the same person $s$.

As was noted above, early German doctrine came to the same conclusion as the Law Lords in Roger Smith. But the reasoning was nonetheless significantly different. With some amendments, the proposed formalism is able to capture some of these differences. British doctrine focused on the notion of impossibility. To attempt the impossible is not prohibited. Again, both legal systems would agree with the natural language expression. And again, they show the same systematic differences to disambiguate this sentence. German law requires again that the impossibility of the act is something that the actor believes, the sentences occurs within the scope of the belief predicate. Our chosen solution can formalise this idea without having to extend the logic. Imp, nec and poss are again de dicto predicates, and the complex sentence can therefore occur at the argument position of the de dicto belief-predicate.

$$
B^{\bullet \circ}\left(a, \operatorname{Imp}^{\circ}\left(M^{\bullet \bullet}\left(a, x^{\circ}\right)\right)\right)
$$

This is simply derived from sentences of the form (2) above, the general form for believe sentences. But (7) excludes liability. If we wanted to make general statements about this rule-exception structure, which is typical for legal doctrine, we would have to extend our formalism. Leśniewski allowed 
quantification into the predicate position of sentences as well, and a very natural extension of the logic proposed here offers the same possibility. ${ }^{14}$ With this devise, we could express the idea that certain properties of our belief sentence might exclude criminal liability, without having to specify these predicates.

English law behaves again strictly symmetrical. (5) was the corresponding belief-sentence to (2) for English law. The doctrine of impossible attempt requires only that a certain act is impossible de re (as far as the belief-predicate is concerned). Hence we get the corresponding formula for (7) as

$$
\exists x^{\circ}\left(x^{\circ}=b \& \operatorname{Imp}^{\circ}\left(M^{\bullet \bullet}\left(a, x^{\circ}\right)\right) \& B^{\bullet}\left(a, M^{\bullet \bullet}\left(a, x^{\circ}\right)\right)\right)
$$

Again, predicate quantification could help us to express that this is the general exception condition for all offences, not only murder. Note that "impossibility" has been formalised as a de dicto predicate. States of affairs are impossible under (due to) a description. This is closely in line with the results from the legal debate. The distinction between possible and impossible offences, introduced by the Lords in the form of the list quoted above, was immediately criticised as entirely arbitrary. It was pointed out, rightly so it seems to me, that it is possible to transform all cases of possible attempt into cases of impossible attempt (and vice versa) by changing the description of the case. Attempted murder (2) above becomes an impossible attempt, because I could not possibly have shot my victim with this gun. Impossible attempt (f) above becomes a possible attempt, because I could have chosen different food. ${ }^{15}$ There are several proposals in the literature to find a distinction between possible and impossible attempts which is true to the spirit of the Lords, but less arbitrary and not description sensitive. So far, these attempts have failed. ${ }^{16}$ More recently, Duff tried to take these failures serious. He proposes a solution that explicitly quantifies over possible descriptions. If we extend the formalism as indicated above and allow quantification of predicates, it seems possible to give a formal account of this solution (Duff 1995).

So far, we ignored deontic modalities in our account. They were however the staring point for Binding's analysis. English and German law alike require an "intent to commit an offence". Belief that one's actions constitute a breach of a law is part of this requirement. Again, this formulation is

\footnotetext{
${ }^{14}$ Cf. Wojciechowski 1994, p. 165-200.

15 Cf. Williams 1978, p. 397.

${ }^{16}$ For a good overview cf. Simons 1990.
} 
ambiguous. It could mean that I consciously commit an act that is in fact prohibited, but neither do I know necessarily about this prohibition, nor is my description of the act necessarily the same as the one chosen by the criminal law. More concretely: I will typically only know that I'm just about to kill someone, not necessarily that in doing so I also violate Art 212 of the German Criminal Code. Alternatively, we can require that a potential perpetrator knows about the legal status of her actions and describes them in the terminology of the criminal law. Unsurprisingly, we find the same pattern that we have encountered so far. German law opts for a reading with the belief predicate at the leftmost position, and all other modalities embedded.

$$
B^{\bullet \circ}\left(a, \operatorname{Prohb}^{\circ}\left(M^{\bullet \bullet}(a, b)\right)\right)
$$

Prohb - It is prohibited that ${ }^{17}$

English law opts again for the rightmost reading of the belief-predicate, and we get

$$
\exists x^{\circ}\left(\operatorname{Prohib}^{\circ} x^{\circ} \& B^{\bullet \circ}\left(a, C^{\bullet \bullet}\left(a, x^{\circ}\right)\right)\right)
$$

$C$ - Commits.

(10) expresses the legal doctrine: error iuris non nocet - ignorance of the law is no excuse. It is under German law. Or rather would be, if German law would not impute the belief expressed by (9) unless proven otherwise. ${ }^{18}$ Apparently, German law adopted here for reasons of conceptual consistency some pragmatic amendments to the general rule. (9) requires that every offender has intimate knowledge of the criminal law. He must not only know that his actions are prohibited, but he must also use legal vocabulary to describe his actions. Remember that the de dicto predicate "prohibited" induces referential opacity. The relevant legal doctrine is the "parallel evaluation by the layman". This mean that factual premises have to be added, contingent e.g. upon education and intellect of the accused, to move from the description with which he describes his act, to the equivalent description of the criminal law. But these are factual premises and open to proof and refutation. ${ }^{19}$ Even if nothing more is at stake than to move from: $A$ believed to kill $B$ (using his own expression "kill" ) to: $A$ believed to murder $B$. No

\footnotetext{
${ }^{17}$ (9) expresses only a's belief that murder is prohibited for him. This might be the most general form of the legal rule that we can get, because a must not belief that a legally recognised exception applies to him.

18 Cf. Krueger 1994, p. 37.

19 This supports a claim made in Lycan 1979 against Quine.
} 
other from of substitution of co-intensional expressions inside a "o" type is possible.

Analogously, we can differentiate offences of full "mens rea", where the entire norm content occurs inside the scope of the de dicto predicate "prohibited", from offences of "half mens rea" ${ }^{20}$ The criminal law norm: "It is prohibited to kill policeman" can then be read either as

$$
P^{\circ}\left(\forall x^{\circ} O^{\bullet} x^{\circ} \rightarrow M^{\bullet} x^{\circ}\right)
$$

$P$ - prohibited; $O$ - policeman; $M$ - murder.

Where the relevant belief to constitute (at least) an attempted crime requires the (possibly mistaken) belief to kill someone whom you belief to be a policeman or as

$$
\forall x^{\circ} O^{\bullet} x^{\circ} \rightarrow P^{\circ}\left(M^{\bullet} x^{\circ}\right)
$$

where it is necessary and sufficient for the prosecution of anyone violating this norm that the victim is in fact a policeman, even if the offender does not know this.

Note that the "norm content sentence" in (11) (that is the part after the predicate $P$ ) is a complex object. This means firstly that the " $\rightarrow$ " does not function as a truth functional connective. The usual problems of the material implication in norm sentences do not occur. ${ }^{21}$ Secondly, I follow again Leśniewski and leave the ontological status of this object open. The names that are substituted for variables do not "loose" the objects they refer to. Only this reference is irrelevant for the logical rules. It is possible, but not necessary to interpret it as a sentence. It is equally admissible to interpret it intuitively as any other object that is determined up to linguistic description, e.g. as an event or an action. ${ }^{22}$

\section{Outline of the formalism}

For the purpose of this paper, I will give only a very short version of the formal semantics, insofar it deviates from classical logic.

As primitive symbols, we have the logical constants $\neg, \&, \forall,=$ (identity is of type $\bullet$ ); infinitely many de re (object) variables: $x, y, z, z_{1}, \ldots$; infinitely

\footnotetext{
${ }^{20}$ For the distinction in English criminal law doctrine cf. Williams 1978, p. 51.

${ }^{21}$ Haage in 1997 proposes a similar interpretation of legal rules as sentences-like objects, but for entirely different reason.

${ }^{22}$ Cf. Küng, Canty 1970, p. 178, 181.
} 
many de dicto (expression) variables: $x^{\circ}, y^{\circ}, z^{\circ}, z_{1}^{\circ}, \ldots$; infinitely many object parameter: $a, b, c, a_{1}, \ldots$; and infinitely many predicate parameter for each type $t=t_{1}, \ldots, t_{r}$ and $t_{i}=$ "o" or "•" with "•" marking de re and "o" marking de dicto argument positions.

The terms of $L$ in basic notation $(\mathrm{BN})$ are the de re and de dicto variables, and the object parameters.

The formulas of $L$ in $\mathrm{BN}$ are either elemental or complex. Elemental formulas are

$$
t_{1}=t_{2}, \quad P, \quad X, \quad P^{\tau_{1} \ldots \tau_{r}}\left(e_{1}, \ldots, e_{r}\right), \quad X^{\tau_{1} \ldots \tau_{r}}\left(e_{1}, \ldots, e_{r}\right)
$$

so that $t_{1}, t_{2}$ are terms in $\mathrm{BN}$ and for $i=1, \ldots, r$ :

a) if $t_{i}=\bullet$ then $e_{i}$ is a term in $\mathrm{BN}$,

b) if $t_{i}=\circ$ then $e_{i}$ is a (possibly defined) term without free de re variables.

Then $P e_{1} \ldots e_{r}$ is called a formula which is free for exactly those variables where the $e_{1}, \ldots, e_{r}$ are free. ${ }^{23}$

The condition for complex formula of $L$ is:

Let $A, B$ be formulas in $\mathrm{BN}, v$ be a de re or de dicto variable. Then $\neg A$, $A \& B, \forall v A$ are formulas in $\mathrm{BN}$ (sentences are as usual formulas without free variables).

We have the usual definition for $\forall, \rightarrow, \leftrightarrow, \vee$ and definite descriptions.

\section{Semantics}

A universe for $L$ is an arbitrary set $D$. For each $d \in D$ we assume a fictitious object name $\boldsymbol{d} \in \boldsymbol{D}$ which is either an object parameter of $L$ or a new symbol which is not element of $L$. $\boldsymbol{D}$ be the set of these names. We get the formulas and terms of $L_{D}$ from the terms and formulas of $L$ by substituting object names for one or more free object variables (the additional names are not part of the language of $L$ but of the interpreted language $Q D L_{\varphi}$. They are meta-theoretical tools to simplify the semantic rules for the quantifiers. Therefore, they do not appear in de dicto positions, where the linguistical forms of the expressions as used by a speaker play a role). Expressions without object names are called pure expressions.

Unlike in standard interpretations, we do not interpret the predicate parameters, but the elemental de re predicates.

${ }^{23}$ Condition b) expresses the idea that you can not quantify with de re variables into de dicto contexts. 
$P e_{1} \ldots e_{r}$ be a pure formula in basic notation, $P$ predicate parameter of type $t_{1}, \ldots, t_{r}$, so that for each $i=1, \ldots, r$ :

- if $t_{1}=\bullet$ then $e_{i}$ is the alphabetically first de re variable different from $e_{1}, \ldots, e_{i-1}$,

- if $t_{i}=\circ$ then $e_{i}$ is a pure description (parameter, definite description).

Let $x_{1}, \ldots, x_{k}$ be the alphabetically first free de re variables in $P e_{1} \ldots e_{r}$ $(0 \leq k \leq r)$. Then we call this formula an elemental predicate in $x_{1}, \ldots, x_{k}$ and introduce the metatheoretical abbreviation $E^{k}$. From $E^{k}$ we derive $E n_{1} \ldots n_{k}$ by substituting terms $n_{i}$ for $x_{i}$.

An interpretation for $L$ over $D$ is a function $f$ that fulfils the four conditions:

(I1) $f(\boldsymbol{d})=d$ for all $d \in D$,

(I2) $f(a) \in D$ for all parameters $a$,

(I3) $f\left(E^{0}\right) \in\{W, F\}$ for elemental predicates $E^{0}$ of arity 0 ,

(I4) $f\left(E^{k}\right) \subset U^{k}$ for each elemental predicate $E^{k}$ of arity $k$.

The truth-values of elemental sentences are determined by the following rules

$$
\begin{aligned}
\left|a_{1}=a_{2}\right|_{f} & = \begin{cases}\mathbf{t} & \text { if } f\left(a_{1}\right)=f\left(a_{2}\right) \text { and both exist } \\
\mathbf{f} & \text { otherwise }\end{cases} \\
\left|E a_{1} \ldots a_{k}\right|_{f} & = \begin{cases}\mathbf{t} & \text { if }\left\langle f\left(a_{1}\right), \ldots, f\left(a_{k}\right)\right\rangle \in f\left(E^{k}\right) \\
\mathbf{f} & \text { otherwise }\end{cases}
\end{aligned}
$$

From the rules for complex sentences, only the rules for quantification differ from the usual definitions, and are therefore given:

$$
\begin{aligned}
|\forall x A x|_{f} & = \begin{cases}\mathbf{t} & \text { if }|A \boldsymbol{d}|_{f}=\mathbf{t} \text { for all } d \in D \\
\mathbf{f} & \text { otherwise }\end{cases} \\
\left|\forall x^{\circ} A x^{\circ}\right|_{f} & = \begin{cases}\mathbf{t} & |A b|_{f}=\mathbf{t} \text { for all pure descriptions } \\
\mathbf{f} & \text { (names and sentences) }\end{cases}
\end{aligned}
$$

Again, place constraints prevent me from a more detailed analysis of the similarities and differences to Leśniewski's original approach. I think however that the reader sceptical about the interpretation of some of the formalisations will find it helpful to understand them with a "Leśniewskian mind-set". On of its distinguishing features is the possibility to quantify with de dicto variables, interpreted substitutionally, into de re positions. ${ }^{24}$ The

${ }^{24}$ This distinguishes this approach e.g. from Barcan-Marcus 1972. 
converse is not possible. My own approach started as a quotational approach to the analysis of belief, and was not able to give a convincing intuitive reading of what was introduced above as de re belief, and no convincing analysis at all of deontic modalities. The version of substitutional quantification proposed by Leśniewski seems to overcome these shortcomings. Unwarranted substitution and quantification is blocked, without a commitment to the precise status of the objects whose names are substituted. Quantification of the predicates finally seems to be the natural way forward to give a more general analysis of the general doctrine of attempts, which is independent from every concrete offence as murder or forgery.

\section{Evaluation from a comparative perspective}

What has our formal analysis told us so far? Firstly, we have seen that the legal dispute concerning the interpretation of attempt is not a dispute between a correct and an incorrect understanding of the belief-predicate, at least not as far as purely formal correctness is concerned. Secondly, we have seen how two different legal systems differed systematically in their understanding of some crucial legal modalities. (Modern) German law preferred consistently a de dicto understanding of belief, with the belief predicate if possible at the leftmost position and the other modalities embedded. English law after Roger Smith preferred consistently a de re reading of belief and tried to transpose the belief predicate to the rightmost position, other modalities if possible outside the scope of the belief-predicate. There are now a number of possibilities available to "exploit" theoretically these findings. At least it offers the possibility to ask new questions. So far, we concentrated on a very small segment of the criminal law. We could now ask the question if these regularities can be found in other parts of the criminal law as well, or maybe more interestingly, if private law follows the same patterns. Cross-border comparison between criminal and private law is something not normally envisaged by comparative lawyers, but the abstractness of a formal approach should allow to extend the analysis to this new field of research. Furthermore, it is possible to combine this approach with one of the rare existing attempts to develop a theoretical vocabulary for comparative law. Rodolfo Sacco introduced the notion of a "legal formant", apparently borrowed from comparative linguistics (Sacco 1991). He describes as a legal formant, the smallest parts of a legal system which "carries legal meaning". Unfortunately, and partly due to his informal approach, 
he does not operationalise this notion. His examples are legal rules proper, and ill at ease with his theoretical explanation. As a result, the concept of a legal formant, while promising in principle, remains essentially vague. Our formalisations (2), (3), (5) and (6) could be understood as good candidates for "legal formants". They are not legal rules in themselves. The decision between one of the possible readings of "belief" and "attempt" is prior to any act of parliament. But added to the legal rules on attempt and intention proper, they determine the meaning of these rules and indeed the character of an entire legal system. The laws on attempt show considerable similarities in Germany and England, but the "legal formants", the structural dissimilarities, give the two systems almost opposite meanings, an internalistic and subjectivistic meaning under German law, an externalistic and objectivistic understanding in England. Furthermore, it is now possible to compare directly the formalised versions of the belief predicate, and interpret the findings. The concept of belief, which informed the decision in Roger Smith was at least in our analysis here formulated in terms of the de dicto interpretation, preferred by German law. It might be possible to draw conclusions for the translatability between the two systems. Finally, this comparison can be embedded into a broader epistemological setting. I have mentioned above that both German and English law started with a position according to which Smith was innocent, and reversed this later on into a position which finds him guilty of an attempted crime. If we compare the corresponding formulas which partly explain the meaning of the belief predicate, i.e. (3) and (6), it becomes obvious that the older formulation (6) is considerably more complex and difficult to read. On the other hand, the move from (6) to (3) also entailed that the "attempt" predicate could be attributed to more cases. Using vocabulary from Lakatos, it seems that to abandon Roger Smith and to move to a subjectivist reading of belief was both a theoretically and empirically progressive step (Lakatos 1974). It was theoretically progressive because it resulted in simpler laws, and it was empirically progressive, because more cases where captured under the new law. Formal methods can help us to understand better those features of legal development, which at least to a certain extent is independent from societal influences To understand and appreciate this "inner rationality" of law should make formal analysis worthwhile for the lawyer. 


\section{References}

Barcan-Marcus, R., 1972, "Quantification and ontology", Nous, 240-249.

Binding, K., 1918, Die Normen und ihre Übertretung, Halle.

Blau, U., 1993, Die Logik der Intentionalen Prädikate, Mss. München.

Canty, J., 1970, "Substitutional quantification and Leśniewski quantifiers, Studia Logica, 165-182.

Cresswell, M., 1980, "Quotational theories of propositional attitudes", J. Phil. Log., 17-140.

Dolling, E., 1995, "Real objects and existence", in: The Heritage of Kazimierz Ajdukiewicz, Vito Sinsi (ed.), Amsterdam.

Duff, A., 1995, "Attempted homicide", Legal Theory 1, 149-178.

Dunn, S., and N. D. Belnap, 1968, "The substitutional interpretation of quantifiers", Nous 2, 177-185.

Geppert, K., 1992, 'Zum 'error in persona vel objekto' und zur 'aberratio ictus', insbesondere vor dem Hintergrund der neuen 'Rose-Rosahl-Entscheidung'", Jura, p. 163.

Kotarbiński, T., 1966, Gnosiology (transl. Wojtasiewicz), New York.

Haack, S., 1974, "Mentioning expressions", Logique et Analyse, 277-294.

Kielkopf, Ch., 1977, "Quantifiers in ontology", Studia Logica, 300-307.

Küng, G., 1977, "The meaning of the quantifiers in the logic of Leśniewski", Studia Logica, 309-322.

Leśniewski, S., 1929, "Grundzüge eines neuen Systems der Grundlagen der Mathematik", Fundamenta Mathematicæ 14, 1-18.

Lakatos, I., 1974, "Falsification and the methodology of scientific research programmes" in: Criticism and the Growth of Knowledge, Musgrave (ed.), Cambridge.

Linsky, L., 1972, "Two concepts of quantification", Nous, 224-238.

Lycan, W., 1979, "Does quotation sometimes permit substitution?", Notre Dame J. Formal Logic, 279-280.

Prittwitz, C., 1983, "Zur Diskrepanz zwischen Tatgeschehen und Tätervorstellung", Goltdammer's Archiv für Strafrecht, p. 110.

Quine, W. V. O., 1956, "Quantifiers and propositional attitudes", Journal of Philosophy, 177-206.

Schäfer, B., 1993, Intensional Argumentation im Vertragsrecht, MA diss., München. 
Simons, P., 1982, "On understanding Leśniewski", History and Philosophy of Logic, 165-191.

Srzednicki, J., and V. F. Rickey (eds.), 1984, Leśniewski's Systems. Ontology and Mereology, The Hague, Boston, Lancaster and Wrocław.

Wojciechowski, E., 1994, "Zwischen der Syllogistk und den Systemen von Leśniewski: Eine Rekonstruktion der Quantifizierung der Praedikate", Grazer Philosophische Studien, 165-200.

Williams, G., 1978, Textbook of Criminal Law, London.

Wray, D., "Logic in quotes", 1987, J. Phil Logic, p. 77-110.

Wróblewski, J., 1983, Meaning and Truth in Judicial Decision, Helsinki.

Wróblewski, J., 1974, "Metodologiczne zagadnienia porównywania systemów prawa", Państwo i Prawo.

BURKHARD SCHÄFER

Centre for Law and Society

Edinburgh University

Edinburgh EH8 9YL

e-mail: B.Schafer@ed.ac.uk 